\title{
Spectral Approach to Assessment of Phytoplankton Photosynthesis Rate in the Black Sea Based on Satellite Information: Methodological Aspects of the Regional Model Development
}

\author{
Tatiana Ya. Churilova*a, \\ Vyacheslav V. Suslin ${ }^{b}$, Olga V. Krivenko ${ }^{\text {a }}$, \\ Tatiana V. Efimova ${ }^{a}$ and Nataliia A. Moiseeva ${ }^{a}$ \\ ${ }^{a}$ A.O. Kovalevsky Institute of Marine Biological Research RAS \\ 2 Nakhimov, Sevastopol, 299011, Russia \\ ${ }^{b}$ Marine Hydrophysical Institute RAS \\ 2 Kapitanskaya Str., Sevastopol, 299011, Russia
}

Received 02.05.2016, received in revised form 16.05.2016, accepted 13.10.2016

\begin{abstract}
The work presents the underpinning for using of the spectral approach for assessment of primary productivity indicators based on remote sensing data. Existing information has been analysed. Problems, which should be solved for practical implementation of the spectral model of primary production in the Black Sea based on satellite data, have been identified. It has been shown that application of the regional algorithms for the assessment of the Black Sea primary productivity indicators on the basis of satellite data has improved the accuracy of model assessment of phytoplankton pigment concentration in the sea. Obtained for the last decade data of bio-optical water properties and photo-physiological characteristics of phytoplankton in the Black Sea allow to switch to the new level of regional models, which take into account not only amount, but also the spectral composition of radiation available for photosynthesis. The spectral model takes into account differences in phytoplankton light absorption efficiency between seasons as well as between euphotic zone layers separated by thermocline. Conceptually, this model is more realistic, and could be used not only for operational monitoring of the Black Sea waters, but also for development of predictive models for the sea ecosystem changes.
\end{abstract}

Keywords: primary production, spectral model, satellite information, Black Sea.

DOI: 10.17516/1997-1389-2016-9-4-367-384.

(C) Siberian Federal University. All rights reserved

* Corresponding author E-mail address: tanya.churilova@gmail.com

$$
-367-
$$




\title{
Спектральный подход к оценке скорости фотосинтеза фитопланктона в Черном море по спутниковой информации: \\ методологические аспекты развития \\ региональной модели
}

\author{
Т.Я. Чурилова ${ }^{a}$ В.В. Суслин \\ О.В. Кривенко ${ }^{a}$, Т.В. Ефимова ${ }^{a}$, Н.А. Моисеева ${ }^{a}$ \\ ${ }^{a}$ Институт морских биологических исследований \\ имени А.О. Ковалевского РАН \\ Россия, 299011, Севастополь, пр. Нахимова, 2 \\ ${ }^{\sigma}$ Морской гидрофизический институт РАН \\ Россия, 299011, Севастополь, ул. Капитанская, 2
}

В статье представлена идеология использования спектрального подхода для оценки первично-продукционных показателей морских вод по данным дистанционного зондирования, проанализирован имеющийся задел информации и определены проблемы, которые необходимо решить для практической реализации спектральной модели оценки первичной продукции в Черном море по спутниковым даннылм. Показано, что применение региональных алгоритмов для расчета первично-продукичонных показателей вод Черного моря на основе спутниковой информации позволило значительно повысить точность модельных оценок содержания пигментов фитопланктона. Накопленные за последние годы материаль исследований о биооптических свойствах вод и фотофизиологических характеристиках фитопланктона Черного моря позволяют перейти на принциипиально новый уровень региональных моделей, в которых учитывается изменение не только количества, но и спектрального состава света, доступного фитопланктону в проиессе фотосинтеза. Спектральная модель дает возможность учитывать различия в способности фитопланктона поглощцать солнечную энергию в отдельные сезоны, а также в отдельных слоях зоны фотосинтеза в условиях сезонной температурной стратификации поверхностных вод. Концептуально такая модель более реалистична и может быть использована не только в целях оперативного мониторинга состояния акватории Черного моря, но и для создания прогностических моделей развития его экосистемьл.

Ключевые слова: первичная продукция, спектральная модель, спутниковая информация, Черное море.

\section{Введение}

Первичная продукция является одним из основных показателей ресурсного потен- циала морских экосистем и их биосферных функций, что определяет актуальность исследования закономерностей ее формирования в 
различных районах Мирового океана. Развитие методов дистанционного зондирования и разработка сканеров, выполняющих из космоса измерения восходящего из толщи океана излучения в разных оптических каналах с высоким разрешением по спектру, открывает новые возможности исследования продуктивности экосистем. Использование информации этих оптических сканеров позволяет проводить глобальную оценку продуктивности акватории с высоким пространственным и временным разрешением, что дает возможность контролировать продукционные показатели вод практически в режиме реального времени. Данные зондирования океана из космоса создают базу для мониторинга состояния морских экосистем на масштабе, который соответствует масштабу пространственновременной изменчивости как гидрологических и гидрохимических условий морской среды, так и структурно-функциональных показателей развития фитопланктона, который не может быть обеспечен традиционными крайне трудоемкими и затратными исследованиями на научно-исследовательских судах.

Оценка первично-продукционных показателей вод по спутниковым данным начинается с расчета концентрации хлорофилла $a\left(\mathrm{C}_{a}\right)$ в поверхностном слое вод на основе анализа спектров восходящего из толщи моря излучения. Стандартный продукт «концентрация хлорофилла $a$ в поверхностном слое», предоставляемый на основе информации спутников Sea-viewing Wide Field-of-view Sensor (SeaWiFS), MEdium Resolution Imaging Spectrometer (MERIS) и Moderate Resolution Imaging Spectroradiometer aboard the Terra and Aqua satellites (MODIS-Aqua/Terra), pacсчитывается по алгоритмам NASA, в основу которых положены биооптические показатели океанических вод 1-го типа (Morel, Prieur,
1977). Несмотря на постоянное уточнение стандартного алгоритма NASA (O'Reilly et al., 2000), даже последние версии (ОС4 для SeaWiFS и OC3М для MODIS-Aqua/Terra) не дают адекватной оценки динамики хлорофилла $a$ в Черном море. Стандартный спутниковый продукт «концентрация хлорофилла $a$ » в несколько раз завышает значения концентрации пигмента в глубоководной области Черного моря в летний период и существенно занижает величины этого показателя в период зимне-весеннего «цветения» фитопланктона. Он фактически «не видит» развития этого процесса на акватории бассейна (рис. 1). Для корректной трансформации оптических сигналов, фиксируемых на спутниках, в показатели первичной продуктивности Черного моря требуется развитие алгоритмов, учитывающих региональные особенности оптики его вод.

В преддверии «спутниковой эры» океанографии в начале 90-х гг. прошлого столетия ведущие оптические центры мира начали активное изучение вариабельности биооптических свойств вод различных районов Мирового океана (Bricaud et al., 1995). Исследования были направлены на оценку соотношения между компонентами, поглощающими свет в море, параметризации связи коэффициентов поглощения взвешенным и растворенным веществом с индексом биомассы фитопланктона - хлорофиллом $a$, что требовалось для создания алгоритмов оценки показателей продуктивности вод (содержания хлорофилла $a$, биомассы фитопланктона и первичной продукции) по спутниковой информации. Биооптические исследования последних 20-30 лет открыли неоднородность Мирового океана по оптическим показателям и необходимость развития региональных алгоритмов, учитывающих специфику биооптических характеристик отдельных морских акваторий. 


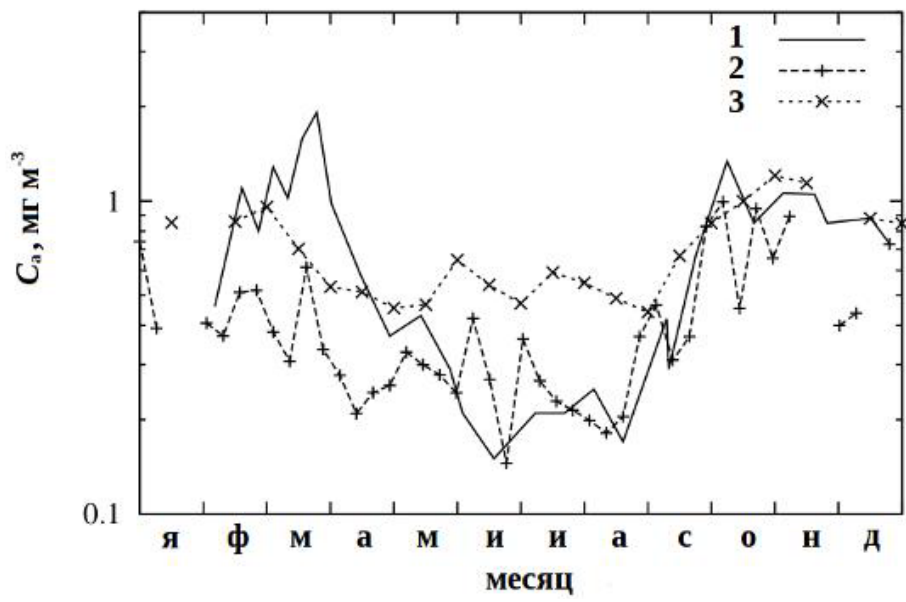

Рис. 1. Результаты сравнения величин концентрации хлорофилла $а$ в глубоководной части Черного моря в 1998 г. по измерениям in situ (1) и восстановленным по спутниковым данным (http://oceandata.sci.gsfc. nasa.gov / SeaWiFS / Mapped / 8Day / 9km /), осредненным для района вокруг точки измерений in situ (土 9 км) для разных моделей: Quasi-Analytical Algorithm - QAA (2) и стандартный продукт NASA (3)

В Черном море измерения поглощения света пигментами фитопланктона, взвешенным и окрашенным растворенным органическим веществом (РОВ) с использованием современных методик (Mueller, Fargion, 2000) впервые нами были проведены в марте 1995 г. В феврале 1998 г. был начат регулярный биооптический мониторинг (Churilova et al., 2004), который проводился как минимум раз в две недели в течение двух лет на двух станциях в глубоководной части Черного моря. Этот мониторинг был инициирован запуском спутника SeaWiFS, и с его результатов начал формироваться черноморский биооптический банк данных, который используется для развития региональных моделей оценки первично-продукционных показателей вод Черного моря по спутниковым данным.

При моделировании первичной продукции (ПП) фитопланктона используются разные модели, но принципиально можно выделить два подхода. Первый подход основан на параметризации зависимости между скоростью фотосинтеза и интегральной величиной фотосинтетически активной радиации (ФАР), рассчитываемой для видимого диапазона излучения (Platt et al., 1991; Финенко и др., 2009). Во втором задействованы величины квантового выхода фотосинтеза/роста ( $\phi)$ и поглощение света пигментами фитопланктона $\left(a_{\mathrm{ph}}(\lambda)\right)$ (Bidigare et al., 1987; Smith et al., 1989; Morel, 1991). Модель расчета ПП с использованием квантового выхода была предложена первоначально без учета спектральных свойств подводной облученности и коэффициента поглощения света. В первоначальном алгоритме присутствовал ФАР и средняя для диапазона видимого излучения величина удельного (нормированного на содержание хлорофилла a) коэффициента $a_{p h}^{*}(\lambda)$ (Kiefer, Mitchell, 1983). Спектральный вариант этой модели получил развитие в более поздних работах (Bidigare et al., 1987; Morel, 1991). Спектральный подход к оценке первичной продукции учитывает (a) изменение спектрального состава света по глубине и (б) особенности поглощения света различного спектрального состава пигментами фитопланктона, что позволяет точно оценивать количество поглощенных фитопланктоном квантов света, используемых в 
фотохимических реакциях с определенной эффективностью, которая оценивается квантовым выходом фотосинтеза.

Развитие моделей ПП фитопланктона было связано с необходимостью разработки алгоритма оценки скорости фотосинтеза на основе ограниченного набора входных параметров (температура, солнечная облученность моря и концентрация хлорофилла $a$ в поверхностном слое моря), получаемых с помощью приборов дистанционного зондирования из космоса. Цель настоящей работы заключается в развитии методологии использования спектрального подхода для оценки первичной продукции в Черном море по данным спутниковых наблюдений. В наши задачи входило: проанализировать имеющийся задел информации, необходимой для реализации спектрального подхода; оценить, что уже сделано и какие проблемы необходимо решить, чтобы реализовать на практике спектральную модель оценки первичной продукции в Черном море, учитывая региональные особенности эффективности поглощения пигментами фитопланктона квантов солнечной энергии и дальнейшего их применения в процессе фотосинтеза.

\section{Описание спектральной модели первичной продукции}

Алгоритм расчета первичной продукции по спутниковым данным с использованием спектрального подхода включает несколько блоков, частично реализованных в региональных моделях для Черного моря:

1) определение концентрации хлорофилла $a$ в поверхностном слое моря по спутниковой информации с помощью региональной биооптической модели (Суслин и др., 2008, 2015);

2) восстановление профиля концентрации хлорофилла $a$ в море на основе се- зонных закономерностей, описанных в (Finenko et al., 2005);

3) оценка спектрального состава проникающей в море радиации по модели (Churilova et al., 2009), которая учитывает биооптические показатели вод Черного моря;

4) оценка скорости фотосинтеза и первичной продукции.

\section{1. Оценка концентрации хлорофилла $a$ в поверхностном слое моря}

Сигнал, регистрируемый оптическими приборами спутников, после атмосферной коррекции оценивает яркость восходящего из толщи моря излучения на определенных длинах волн, которая зависит от рассеяния и поглощения солнечной радиации в море взвешенными частицами (пигментами фитопланктона и неживой компонентой взвеси), РОВ и чистой морской водой. Следует отметить, что наряду с основным пигментом - хлорофиллом $a$, концентрацию которого используют для количественной оценки развития фитопланктона, на регистрируемый сканером сигнал влияет поглощение света всеми пигментами фитопланктона. Многофакторность зависимости яркости восходящего излучения определяет сложность задачи, которую требуется решить, определяя содержание хлорофилла $a$ в поверхностном слое моря по спутниковым данным. Алгоритмы, разработанные для вод Мирового океана, относящихся к 1-му типу (Morel, Prieur, 1977), основываются на эмпирических зависимостях между отношением коэффициентов яркости моря в двух спектральных каналах и концентрацией хлорофилла $a$ в воде (O’Reilly et al., 2000). В водах 2-го типа, к которым относится и Черное море (Суетин и др., 2002), такая зависимость выражена слабо, в первую очередь в силу того, что основным оптически активным компонентом 
этих вод является РОВ (Чурилова и др., 2008). В глубоководной части Черного моря даже в зимний период, когда концентрация хлорофилла $a$ в поверхностном слое достигает максимальных за год величин, вклад пигментов фитопланктона в общее поглощение света на длине волны 440 нм составляет менее $50 \%$ (Чурилова и др., 2015). Летом в верхнем квазиоднородном слое (ВКС) моря относительное поглощение света пигментами фитопланктона значительно меньше (Churilova, Berseneva, 2004).

Имеющиеся биооптические данные (Churilova, Berseneva, 2004; Churilova et al., 2004, 2008) были использованы для разработки регионального алгоритма оценки концентрации хлорофилла в Черном море по спутниковым данным (Суслин и др., 2008). Данный алгоритм основан на разделении поглощения света на две составляющие - поглощение света непосредственно пигментами фитопланктона и поглощение $\mathrm{POB}\left(a_{\mathrm{CDOM}}(\lambda)\right)$ в сумме с неживым взвешенным веществом $\left(a_{\mathrm{NAP}}(\lambda)\right)$
$\left(a_{\mathrm{CDM}}(\lambda)=a_{\mathrm{CDOM}}(\lambda)+a_{\mathrm{NAP}}(\lambda)\right)$. В алгоритме предложено применять два индекса, которые вычисляются как отношения величин коэффициента яркости моря $\left(R_{\mathrm{RS}}\right)$ на выбранных длинах волн $\lambda_{1}, \lambda_{2}, \lambda_{3}: 490,510$ и 550 нм - для SeaWiFS; 488, 531 и 547 нм - для MODIS; 490, 510 и 560 нм - для MERIS (Суслин и др., 2008, $2015)$. Использование индексов $R_{\mathrm{RS}}\left(\lambda_{3}\right) / R_{\mathrm{RS}}\left(\lambda_{2}\right)$; $R_{\mathrm{RS}}\left(\lambda_{2}\right) / R_{\mathrm{RS}}\left(\lambda_{1}\right)$, которые слабо чувствительны к ошибкам атмосферной коррекции и обратному рассеянию света взвесью, повышает точность алгоритма. Сравнение модельных оценок с измерениями in situ приведено на рис. 2. Показано, что предлагаемый региональный алгоритм более точно восстанавливает концентрацию хлорофилла по спутниковым данным, чем стандартные алгоритмы NASA (рис. 6, 7 в: Суслин и др., 2008).

\section{2. Восстановление}

\section{вертикального профиля хлорофилла}

На следующем этапе расчетов решается задача восстановления вертикального
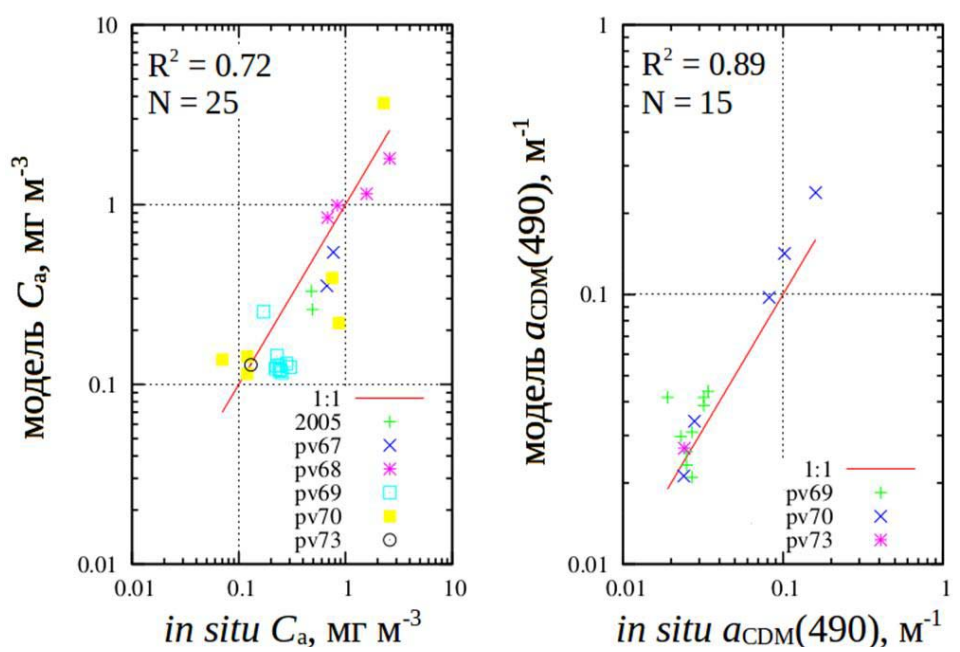

Рис. 2. Результаты сравнения день в день измерений in situ концентрации хлорофилла $a\left(\mathrm{C}_{a}\right)$ и коэффициента поглощения света окрашенным РОВ в сумме с неживым взвешенным веществом $\left(a_{\mathrm{CDM}}(490)\right)$ с модельными расчетами по региональному алгоритму с использованием данных цветового сканера MODIS-Aqua; приведены данные экспедиций НИС «Профессор Водяницкий» PV 67 - 70, 73; НИС «Владимир Паршин» 2005 г. (Суслин и др., 2015) 
распределения $\mathrm{C}_{a}$ в водной толще на основе его величины в поверхностном слое. Известно (Gordon, McGlunev, 1975), что регистрируемый оптическими сканерами спутников сигнал формируется в поверхностном слое воды, соответствующем одной оптической глубине (ל, безразмерная величина). Формула определения оптической глубины (Kirk, 1994)

$$
\zeta=\mathrm{k}_{\mathrm{d}} \times \mathrm{z},
$$

где $\mathrm{k}_{\mathrm{d}}$ - показатель диффузного ослабления, $\mathrm{m}^{-1} ; \mathrm{z}$ - глубина, м.

Для первой оптической глубины $(\zeta=1)$ и нижней границы зоны фотосинтеза $(\zeta=4,6)$ имеем следующие выражения:

$$
\begin{aligned}
& 1=\mathrm{k}_{\mathrm{d}} \times \mathrm{z}_{1} ; \\
& 4,6=\mathrm{k}_{\mathrm{d}} \times \mathrm{z}_{4,6 .} .
\end{aligned}
$$

Принимая величину $\mathrm{k}_{\mathrm{d}}$ постоянной в пределах зоны фотосинтеза, можно оценить соотношение поверхностного слоя, «видимого» сканером $\left(\mathrm{z}_{1}\right)$, с зоной фотосинтеза $\left(\mathrm{z}_{4,6}\right)$ :

$$
\mathrm{z}_{1} / \mathrm{z}_{4,6}=1 / 4,6 \sim 0,22 .
$$

Однако доминирующий вклад РОВ в общее поглощение света и относительно высокий коэффициент показателя экспоненты $\left(\mathrm{S}_{\mathrm{CDOM}} \sim 0,018\right.$ нм$\left.^{-1}\right)$ спектрального распределения его коэффициента поглощения $a_{\mathrm{CDOM}}(\lambda)$ приводит к тому, что значение коэффициента $\mathrm{k}_{\mathrm{d}}$ в подповерхностном слое в моря $\sim$ в 1,6 раза превышает среднюю по эвфотическому слою величину $\mathrm{k}_{\mathrm{d}}$ (Churilova et al., 2009). Поэтому «видимый» спутником слой будет составлять меньшую часть зоны фотосинтеза, чем показывает наша приблизительная оценка (т.е. $\left.\mathrm{z}_{1} / \mathrm{z}_{4,6}<0,22\right)$.
В теплый период года глубина перемешивания поверхностных вод Черного моря определяется положением сезонного термоклина. В среднем толщина ВКС варьирует от 10 до 20 м (Иванов, Белокопытов, 2011), и располагается он в верхней части зоны фотосинтеза, протяженность которой в глубоководной области моря летом достигает 50 м (Чурилова и др., 2014). Вертикальное распределение хлорофилла $a$ в пределах ВКС в Черном море в летнеe (Finenko et al., 2005; Чурилова и др., 2014) и зимнее время (Finenko et al., 2005; Чурилова и др., 2015) чаще всего однородно. Учитывая это, можно принять, что регистрируемый сканером спутника сигнал на протяжении большей части года отражает оптические свойства вод ВКС. Неоднородное распределение $\mathrm{C}_{a}$ в пределах первой оптической глубины возможно в период формирования температурной стратификации вод (в апреле-мае), когда наблюдается относительно узкий и многоступенчатый по структуре ВКС (Иванов, Белокопытов, 2011), что необходимо учитывать в алгоритмах восстановления вертикальных профилей содержания пигментов.

Зимой, после разрушения сезонной стратификации вод, протяженность ВКС в глубоководной части Черного моря заканчивается верхней границей основного пикноклина, положение которой по глубине может варьировать от 25-30 м в центрах стационарных циклонических круговоротов до 50-70 м на их периферии, а в зоне антициклонических образований и струе основного Черноморского течения может достигать 100 м и более (Иванов, Белокопытов, 2011). В глубоководной области моря зона фотосинтеза в зимнее время составляет $\sim 30$ м (Churilova et al., 2009; Чурилова и др., 2015). В зоне подъема вод глубина ВКС сопоставима с зоной фотосинтеза, в пределах которой наблюдается практически однородное распределение $\mathrm{C}_{a}$. 
В районах опускания вод за счет вертикального перемешивания слой существования фитопланктона в два и более раз превышает зону фотосинтеза.

С точки зрения оценки продуктивности вод в моделях можно ограничиться слоем фотосинтеза, решив, что принимать за нижнюю его границу - глубину проникновения $1 \%$ либо 0,1 \% света от падающей на поверхность моря ФАР. Выбор, очевидно, будет связан с относительным вкладом слоя (1-0,1) \% ФАР в общую продукцию фитопланктона в зоне фотосинтеза. Учитывая слабую освещенность, выбор будет определяться относительным обилием фитопланктона (или $\mathrm{C}_{a}$ ) в данном слое. Определение глубины зоны фотосинтеза по акватории моря легко реализуемо на основе спутниковых данных и имеющейся биооптической модели распространения света в водной толще (Churilova et al., 2009).

Внутриклеточная концентрация хлорофилла $a$ и фотосинтетические характеристики фитопланктона зависят от условий существования водорослей, к которым они адаптируются в процессе роста (Falkowski, 1980). В ВКС средняя величина освещенности определяет адаптивные изменения в структуре и функциях фитопланктона (Cullen, Lewis, 1988). Зимой в Черном море соотношение между глубиной ВКС и протяженностью зоны фотосинтеза существенно варьирует по акватории. Поэтому необходима более точная оценка условий существования фитопланктона в перемешанном слое в этот период, что позволит отслеживать пространственную неоднородность развития фитопланктона по изменению скорости фотосинтеза и прогнозировать развитие зимне-весеннего «цветения» фитопланктона в море. В настоящее время оценить глубину залегания градиентов плотности позволяют достаточно сложные гидродинамические модели (Кубряков и др., 2012), и в перспективе на основе их интеграции с биооптическими моделями задача уточненной оценки световых условий существования фитопланктона в перемешанном слое может быть практически реализована.

Летом после формирования сезонной стратификации поверхностных вод вертикальный профиль распределения $\mathrm{C}_{a}$ в Черном море характеризуется одним глубинным максимумом, расположенным вблизи нижней границы зоны фотосинтеза (Finenko et al., 2005, Чурилова и др., 2014). Изменение с глубиной $\mathrm{C}_{a}$ в теплый период года может быть описано функцией распределения Гаусса, параметры которой были найдены на основе обобщения многолетних данных о вертикальном распределении $\mathrm{C}_{a}$ в Черном море (Finenko et al., 2005), что позволило восстанавливать вертикальное распределение $\mathrm{C}_{a}$ по данным о величине $\mathrm{C}_{a}$ в поверхностном слое (раздел 1). Поскольку глубинный максимум $\mathrm{C}_{a}$ расположен на глубине, соответствующей проникновению 1 \% ФАР, модельные расчеты следует проводить до глубины, куда проникает 0,1 \% ФАР, что позволяет учитывать вклад слоя максимальных концентраций $\mathrm{C}_{a}$ (Finenko et al., 2005; Чурилова и др., 2014) в интегральную продукцию фитопланктона в море.

\section{3. Оценка спектрального состава проникающей в море радиации}

Световые условия в море определяются потоком солнечной энергии, падающей на поверхность, и оптическими свойствами морской среды, а именно поглощением и рассеянием света (Kirk, 1994). В последнее десятилетие в северо-западной, глубоководной западной и восточной частях Черного моря проводились многочисленные измерения (Churilova et al., 2004; Чурилова и др., 2008, $2014,2015)$ поглощения света фитопланктоном и взвешенным веществом с использова- 
нием современных методик (Mueller, Fargion, 2000), что позволило с высоким спектральным разрешением выполнить параметризацию поглощения света основными оптически активными компонентами и выявить сезонные особенности формирования биооптических характеристик вод Черного моря (Чурилова и др., 2008), уточнение которых продолжается до настоящего времени.

Коэффициент поглощения света всем взвешенным веществом $a_{p}(z, \lambda)$ зависит от относительного поглощения света неживой взвесью, концентрации пигментов в море, видового состава фитопланктона, размеров клеток и внутриклеточной концентрации пигментов (Kirk, 1994; Bricaud et al., 1995; Чурилова и др., 2014). Параметризация связи между $a_{p}(\lambda)$ и $C_{a}$, выполнена для разных районов моря, теплого и холодного периодов, для глубин выше и ниже сезонного термоклина. Она отражает влияние факторов среды на фитопланктонную составляющую $\left(a_{\mathrm{ph}}(\lambda)\right)$ в поглощении света всем взвешенным веществом и значительное (до двух раз) увеличение вклада неживой компоненты $\left(a_{\mathrm{NAP}}(440)\right)$ в величину $a_{p}(440)$ в прибрежных водах (Чурилова и др., 2008).

Спектральное распределение коэффициента $a_{C D O M}(\lambda)$ описывается экспоненциальной функцией:

$$
\begin{aligned}
& a_{\text {СDОM }}(\lambda)=a_{\text {СDОM }}\left(\lambda_{0}\right) \times \\
& \times \exp \left[-S_{\text {СDOM }}\left(\lambda-\lambda_{0}\right)\right],
\end{aligned}
$$

где $S_{C D O M}-$ коэффициент, характеризующий изменение $a_{C D O M}(\lambda)$ по спектру, нм$^{-1} ; \lambda_{0}=490$ нм. В настоящей версии модели были использованы следующие допущения: 1) гомогенное вертикальное распределение $a_{C D O M}(\lambda)$ и $S_{C D O M}$; 2) незначительное влияние NAP на величину $S_{C D M}$, что дает возможность в качестве $S_{C D M}$ использовать полученные in situ средние зна- чения $S_{C D O M}$, характерные для прибрежных $\left(S_{C D O M}=0,020 \mathrm{HM}^{-1}\right)$ и глубоководных $\left(S_{C D O M}=\right.$ 0,018 нм$^{-1}$ ) районов моря (Чурилова и др., 2008). Для поверхностного слоя величину $a_{C D M}(490)$ рассчитывали по региональному алгоритму (Суслин и др., 2008, 2015). В настоящее время проводятся детальные исследования пространственно-временной изменчивости $a_{C D O M}(\lambda), a_{\mathrm{NAP}}(\lambda)$ в глубоководном и прибрежном районах Черного моря, что позволит выявить сезонные особенности их вертикальной структуры для уточнения модели.

В основу регионального подхода для расчета подводной облученности по спектральной модели $E_{d}(z, \lambda)$ (Churilova et al., 2009) положена модель Бедфорда (Platt et al., 1991), которая была модифицирована на основании результатов параметризации поглощения света основными оптически активными компонентами в Черном море. В модели использовали алгоритм корректной оценки обратного рассеяния света частицами взвеси по спутниковым данным (Суетин и др., 2002). Результаты модельных расчетов изменения $E_{d}(\lambda)$ с глубиной представлены на рис. 3. Для сравнения с модельными оценками были взяты данные измерений подводной облученности, выполненные в открытых водах западной части Черного моря в июне 1996 г. на НИС «Трепанг», когда подводную облученность измеряли погружным радиометром (Biospherical Instruments Inc.) на семи каналах $(412,5,443,5,489,7,509,3,554,4,665,6$ и 683,7 нм). Абсолютные величины падающей на поверхность солнечной радиации различались, поэтому сравнивали спектральный ход ФАР в относительных единицах $E_{d}(\lambda) / E_{d / \max }$ (где $E_{d / \max }=E_{d}(0, \lambda)$ ) для одинаковых оптических глубин, соответствующих проникновению 25, 7 и $2 \% \Phi^{\text {ФАР }}$ (рис. 4). Модельные спектры проникающей радиации $E_{d}(\lambda)$ по форме практически совпали с результатами 


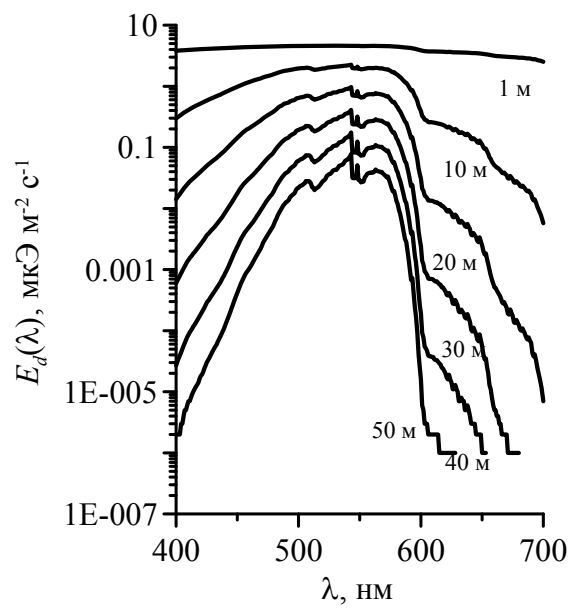

Рис. 3. Результаты модельных расчетов спектрального распределения проникающей солнечной радиации $E_{d}(\lambda)$ в глубоководном районе моря в теплый период года при концентрации хлорофилла $a$ в поверхностном слое моря $\mathrm{C}_{a}=0,2$ мг $\mathrm{m}^{-3} ; S S T=20^{\circ} \mathrm{C}$; поглощении РОВ $a_{C D O M}(440)=0,1 \mathrm{M}^{-1}$ и обратном рассеянии света частицами $b_{b p}(555)=0,01 \mathrm{~m}^{-1}$ (Churilova et al., 2009)
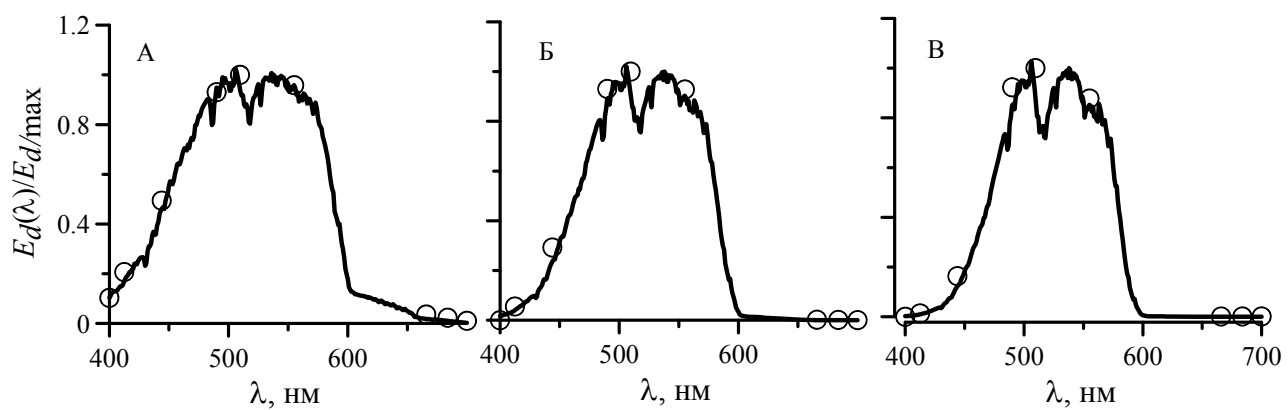

Рис. 4. Сравнение спектрального распределения относительной величины проникающей солнечной радиации $\left(E_{d}(\lambda) / E_{d / m a x}\right)$ в глубоководном районе моря в теплый период года при концентрации хлорофилла $a$ в поверхностном слое моря $\mathrm{C}_{a}=0,2$ мг м $^{-3}$, полученного по модельным расчетам и данным измерений (кружки) для глубин с 25- (А), 7- (Б) и 2\%-ным (В) уровнем облученности (ФАР) (Churilova et al., 2009)

измерений. Рассчитанная величина среднего по слою 0-50 м коэффициента вертикального ослабления облученности в видимом диапазоне $\left(0,131 \mathrm{~m}^{-1}\right)$ также соответствовала измеренному значению $\left(0,128 \mathrm{~m}^{-1}\right)$. Совпадение модельных оценок с измеренными значениями свидетельствует об адекватности региональной спектральной модели подводной облученности. Анализ чувствительности модели показал, что форма спектрального распределения $E_{d}(\lambda)$, в особенности ее коротковолно- вая часть, зависит в основном от корректной оценки $a_{C D о м}(\lambda)$. Поэтому получение новых данных о пространственной и временной изменчивости этого показателя в Черном море крайне важно для уточнения модели формирования светового поля в водах данного бассейна.

\section{4. Скорость фотосинтеза}

Развитие спектрального подхода в моделировании скорости фотосинтеза и роста 
микроводорослей началось с простой биооптической модели для оценки первичной продукции (Bidigare et al., 1987), в основу которой была положена базовая закономерность: скорость фотосинтеза фитопланктона зависит от уровня ФАР в среде и фотосинтетической способности микроводорослей к ее утилизации. Величина последней определяется двумя параметрами, характеризующими эффективность основных этапов синтеза органического вещества растительными клетками: 1) спектральным распределением коэффициента поглощения света, который отражает способность пигментного комплекса клеток поглощать кванты в пределах всего видимого диапазона излучения; 2) квантовым выходом фотосинтеза, который характеризует эффективность использования поглощенных квантов в процессе синтеза органического вещества. Модель имеет следующий вид:

$$
\operatorname{PP}(z)=12000 \phi(z) \times \operatorname{PUR}(z),
$$

где $\mathrm{PP}(\mathrm{z})$ - валовая первичная продукция на разных глубинах (z), мгС сут ${ }^{-1} \mathrm{M}^{-3} ; 12000-$ коэффициент перехода от молей к мг углерода; $\phi(z)$ - квантовый выход фотосинтеза, Моль C $\Im^{-1}$; PUR - количество поглощенных квантов фотосинтетически активной радиации, Э сут ${ }^{-1} \mathrm{M}^{-3}$.

\section{1. Поглощенная фитопланктоном солнечная энергия}

Спектральный подход к оценке скорости фотосинтеза фитопланктоном учитывает спектральный состав проникающего в море солнечного излучения $\left(E_{d}(\lambda)\right)$. Описанная выше региональная модель подводной облученности позволяет проводить оценку величины этого параметра с высоким спектральным (1 нм) и пространственным (1 м по глубине) разрешением. Результаты модель- ных оценок $E_{\mathrm{d}}(\mathrm{z}, \lambda)$ могут быть использованы в расчетах величины PUR(z) по формуле

$$
\operatorname{PUR}(\mathrm{z})=\int_{400}^{700} E_{d}(z, \lambda) \times a_{p h}(z, \lambda) d \lambda,
$$

где $a_{\mathrm{ph}}(\mathrm{z}, \lambda)$ - коэффициент поглощения света пигментами фитопланктона $\left(\mathrm{m}^{-1}\right)$.

Связь коэффициентов $a_{\mathrm{ph}}(\mathrm{z}, \lambda)$ с концентрацией хлорофилла $a$ в море в общем виде описывается степенной функцией:

$$
a_{\mathrm{ph}}(\mathrm{z}, \lambda)=\mathrm{A}(\lambda) \times \mathrm{C}_{a}(\mathrm{z})^{\mathrm{B}(\lambda)},
$$

где $\mathrm{A}(\lambda)$ и $\mathrm{B}(\lambda)$ - коэффициенты, которые определяются для видимого диапазона излучения с шагом в 1 нм (Bricaud et al., 1995; Churilova et al., 2004; Чурилова и др., 2014, 2015). Коэффициент $\mathrm{A}(\lambda)$ (с размерностью м ${ }^{2}$ $\mathrm{M \Gamma C}_{a}^{-1}$ ) фактически соответствует $a_{\mathrm{ph}}(\lambda)$, когда $\mathrm{C}_{a}=1$ мг м ${ }^{-3}$. Коэффициент $\mathrm{B}(\lambda)$ безразмерный, его величина характеризует снижение удельного (нормированного на величину $\mathrm{C}_{a}$ ) коэффициента поглощения $a_{p h}^{*}(\lambda)$ с повышением содержания хлорофилла $a$ в воде. Величина $a_{p h}^{*}(\lambda)$ зависит от внутриклеточного содержания пигментов, размерной и видовой структуры фитопланктонного сообщества (Morel, Bricaud, 1981).

Проведенные в Черном море в разное время года измерения показали, что удельные коэффициенты поглощения пигментами фитопланктона коротковолнового излучения (в синей части спектра) в ВКС достоверно различаются по сезонам (рис. 5) (Чурилова и др., 2014, 2015). Различие величин летом и поздней осенью - в начале зимы обусловлены адаптивными изменениями состава пигментов фитопланктона и их внутриклеточной концентрации в ответ на изменение условий существования водорослей в слое ВКС (главным образом световых). Для теплого периода, 

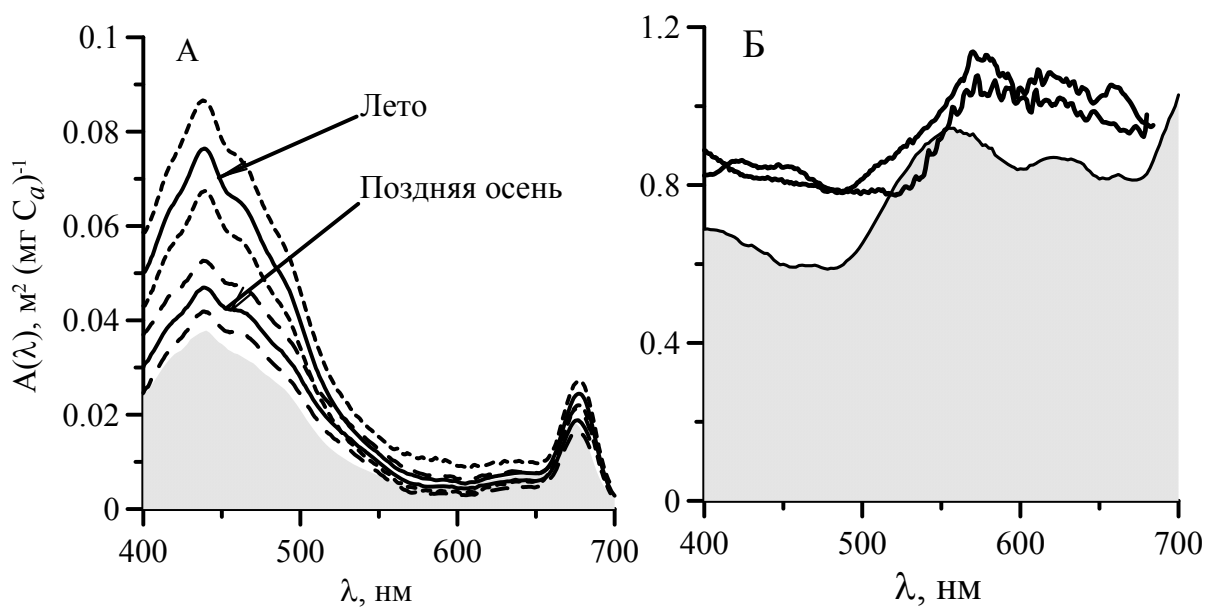

Р ис. 5. Коэффициенты $\mathrm{A}(\lambda)$ ( \pm стандартное отклонение) (А) и В $(\lambda)$ (Б) параметризации связи поглощения света пигментами фитопланктона $\left(a_{\mathrm{ph}}(\lambda)\right)$ с концентрацией хлорофилла $a\left(\mathrm{C}_{a}\right)$, которая описывается

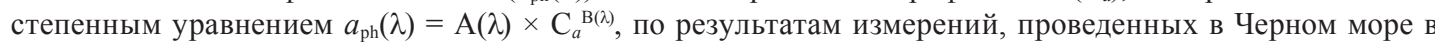
летний и позднеосенний периоды года (по Чурилова и др., 2014); серым показаны величины $\mathrm{A}(\lambda)$ и $\mathrm{B}(\lambda)$, рассчитанные по (Bricaud et al., 1995)

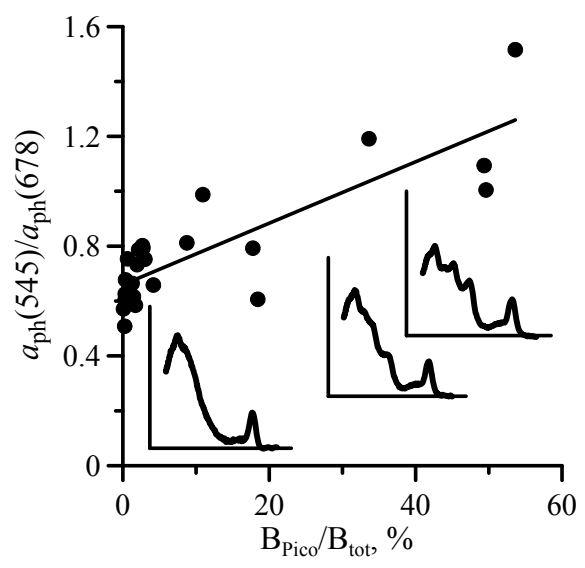

Рис. 6. Зависимость величины отношения коэффициентов поглощения света пигментами фитопланктона на длинах волн 545 и 678 нм $\left(a_{\mathrm{ph}}(545) / a_{\mathrm{ph}}(678)\right)$ от вклада пикофракции в общую биомассу фитопланктона ( $\left.\mathrm{B}_{\mathrm{pico}} / \mathrm{B}_{\mathrm{tot}}, \%\right)$; вставка - соответствующее изменение формы спектров $a_{\mathrm{ph}}(\lambda)$ (Чурилова и др., 2008)

когда зона фотосинтеза разделена сезонным термоклином на два специфических по условиям слоя, показано различие между ВКС и подтермоклинными водами по величинам удельных коэффициентов поглощения света и форме спектров (рис. 6). Эти различия определяются, главным образом, изменением спектрального состава света и адаптивной перестройкой фитопланктонного сообщества - в глубоких слоях эвфотической зоны развиваются преимущественно сине-зеленые водоросли, в то время как в ВКС доминируют относительно крупные динофлагелляты (Чурилова и др., 2008).

Чтобы учесть рассмотренные особенности при моделировании процессов первично- 
продукционного синтеза, необходима параметризация связи коэффициентов поглощения света пигментами фитопланктона с концентрацией хлорофилла $a$ для разных сезонов и слоев зоны фотосинтеза, что позволит точнее оценивать величину PUR(z), а следовательно, в целом повысит точность модельных оценок ПП. В настоящее время из-за отсутствия данных натурных наблюдений остается открытым вопрос параметризации связи между величинами $a_{\mathrm{ph}}(\lambda)$ и $\mathrm{C}_{a}$ в весенний период, когда в поверхностном слое вод начинает формироваться сезонный термоклин. Кроме того, до сих пор не выявлены сезонные особенности светопоглощающих характеристик фитопланктона в прибрежных водах, которые могут отличаться от значений, полученных в глубоководных районах, в силу принципиально различных механизмов формирования гидрохимической и оптической структуры вод в неретических и пелагических водах.

\section{2. Квантовый выход фотосинтеза}

Квантовый выход фотосинтеза характеризует эффективность использования поглощенных фитопланктоном квантов энергии в процессе фотосинтеза и не зависит от спектральных свойств поглощенной энергии (Lewis et al., 1985; Morel et al., 1987). Поэтому при моделировании скорости фотосинтеза и роста микроводорослей квантовый выход фотосинтеза рассматривается как спектрально независимый показатель (Kiefer, Mitchell, 1983; Bidigare et al., 1987; Smith et al., 1989; Morel, 1991; Wozniak et al., 2007). Теоретически возможный максимум этого показателя $\left(\phi_{m}\right)$ составляет 0,125 Моль С (Э) ${ }^{-1}$ (Kok, 1948). Однако полученные для природного фитопланктона значения $\phi_{m}$ не превышают 0,050,1 Моль С (Э)-1 (Babin et al., 1996; Sakshaug et al., 1997; Marra et al., 2000; Wozniak et al., 2007; Churilova et al., 2008). Снижение кванто- вого выхода от его максимальной величины может быть связано с влиянием целого ряда факторов, основной из которых освещенность (Kiefer, Mitchell, 1983; Morel, 1991; Wozniak et al., 2007). Снижение квантового выхода фотосинтеза относительно его максимального уровня при увеличении освещенности в среде (ФАР) описывается уравнением

$$
\phi=\phi_{m} \times\left(K_{\phi} /\left(K_{\phi}+P A R\right)\right),
$$

где $K_{\phi}-$ интенсивность света, при которой $\phi$ достигает величины $\phi_{\mathrm{m}} / 2$; PAR - это ФАР (Kiefer, Mitchell, 1983).

Очевидно, что при интенсивностях света, превышающих пороговое значение для насыщения квантового выхода, его величина практически линейно уменьшается с ростом ФАР. Поэтому во всех районах Мирового океана наблюдается увеличение квантового выхода с глубиной (Bidigare et al., 1987; Smith et al., 1989; Wozniak et al., 2007). В нижней части зоны фотосинтеза величины квантового выхода максимальны, а в поверхностных водах в зависимости от уровня инсоляции моря величина $\phi$ на 2-3 порядка меньше, чем $\phi_{m}$ (Wozniak et al., 2007). Важным фактором, влияющим на величину $\phi_{m}$, является доля фотопротекторных пигментов в общем содержании пигментов в клетках (NPP) (Babin et al., 1996; Marra et al., 2000; Wozniak et al., 2007), поскольку энергия, поглощенная фотопротекторными пигментами, не используется далее в процессе фотосинтеза. Снижение эффективности работы реакционных центров (РЦ) фотосистемы 2 в условиях слабой биогенной обеспеченности клеток водорослей (Маторин, Рубин, 2012) также может рассматриваться как причина снижения величины $\phi_{m}$ в природных условиях (Babin et al., 1996).

Кроме этого, фотодеструкция РЦ при экстремально высокой облученности ведет к 
снижению максимальной квантовой эффективности фотохимических процессов (Маторин, Рубин, 2012). Зависимость квантового выхода от условий среды в общем виде можно представить следующим образом:

$$
\begin{aligned}
& \phi=\phi_{m} \times \mathrm{f}(\mathrm{E}, \mathrm{T}) \times \mathrm{f}(\mathrm{NPP}) \times \\
& \times \mathrm{f}(\mathrm{N}) \times \mathrm{f}\left(\mathrm{PAR}_{\mathrm{inh}}\right),
\end{aligned}
$$

где $\mathrm{f}(\mathrm{E}, \mathrm{T}), \mathrm{f}(\mathrm{NPP}), \mathrm{f}(\mathrm{N}), \mathrm{f}\left(\mathrm{PAR}_{\mathrm{inh}}\right)-$ факторы влияния света и температуры, доли фотопротекторных пигментов, биогенной обеспеченности, фотодеструкции РЦ соответственно (Wozniak et al., 2007).

Световой фактор определяет практически 80 \% общей вариабельности ф (Wozniak et al., 2007). Показано, что на величину ф влияет именно количество поглощенных пигментами водорослей квантов света - PUR (Bidigare et al., 1987; Smith et al., 1989; Wozniak et al., 2007). Величина PUR зависит не только от уровня ФАР в среде, но и от его спектральных свойств, а также от способности водорослей поглощать кванты света. Для нивелирования негативного влияния фотопротекторных пигментов на оценку квантового выхода в расчетах используют поглощение света фотосинтетически активными пигментами. Для Балтийского моря на основе анализа многочисленных биооптических данных предложено уравнение для оценки фактора $\mathrm{f}(\mathrm{E}, \mathrm{T})$, который на 80 \% определяет вариабельность величины $\phi$ :

$$
\begin{aligned}
& \mathrm{f}(\mathrm{E}, \mathrm{T})=\left[1-\exp \left(-\mathrm{PUR}^{*}{ }_{\mathrm{psp}} /\right.\right. \\
& \left.\left.\mathrm{KPUR}^{*}{ }_{\mathrm{psp}}(\mathrm{T})\right)\right] \times \\
& \times \mathrm{KPUR}^{*}{ }_{\mathrm{psp}}(\mathrm{T}) / \mathrm{PUR}^{*}{ }_{\mathrm{psp}},
\end{aligned}
$$

где PUR* ${ }_{\text {psp }}$ - количество квантов, поглощенных фотосинтетически активными пигментами при единичной концентрации хлорофилла $a\left(Э\right.$ сут $\left.^{-1} \mathrm{MrC}_{a}{ }^{-1}\right) ; \mathrm{KPUR}_{\mathrm{psp}}^{*}(\mathrm{~T})-$ коэффициент, характеризующий влияние температуры на $a_{p h}^{*}(\lambda)($ Wozniak et al., 2007).

В Черном море количество данных параллельных измерений световых зависимостей скорости фотосинтеза и спектров поглощения света фитопланктоном, которые позволяют рассчитывать величину $\phi_{m}$, очень ограничено (Churilova et al., 2008). Однако существует возможность адаптации алгоритма расчета квантового выхода, предложенного для Балтийского моря, воды которого также относятся ко второму типу. Первый вариант реализации адаптации представлен в (Churilova, Suslin, 2010). Оценка общего поглощения света всеми пигментами фитопланктона является реальной задачей для Черного моря (см. п. 4.1). Величину $\mathrm{PUR}_{\text {psp }}^{*}$ можно оценить по величине NPP, используя зависимость NPP от световых условий существования фитопланктона в слое ВКС (Babin et al., 1996).

На настоящий момент для реализации спектрального подхода к оценке ПП в Черном море по спутниковым данным разработана большая часть необходимых региональных моделей, собран и проанализирован банк биооптических показателей вод и фотофизиологических характеристик черноморского фитопланктона, выявлены основные закономерности изменчивости этих показателей в глубоководной и прибрежной частях моря. Все это позволяет реализовать региональную спектральную модель оценки первичнопродукционных показателей по спутниковым данным в Черном море.

\section{Заключение}

Высокое содержание окрашенного РОВ в поверхностных водах Черного моря определяет особенности биооптических свойств вод данного бассейна (тип 2) и существенно ограничивает возможность использования стандартных алгоритмов оценки первично- 
продукционных показателей вод по спутниковым данным, которые основаны на допущениях, принятых для океанических вод 1-го типа. Применение региональных алгоритмов для расчета содержания хлорофилла $a$ и первичной продукции Черного моря по данным дистанционного зондирования позволило значительно увеличить точность модельных оценок. Накопленные за последние годы материалы исследований о биооптических свойствах вод и фотофизиологических характеристиках фитопланктона Черного моря дают возможность перейти на принципиально новый уровень региональных моделей, в которых учитывается изменение не только количества, но и спектрального состава света, доступного фитопланктону в процессе фотосинтеза. Предлагаемая спектральная биооптическая модель оценки первичной продукции базируется на обобщении данных многолетних наблюдений и позволяет учитывать различия в способности фитопланктона поглощать солнечную энергию в отдельные сезоны, а также в отдельных слоях зоны фотосинтеза в условиях сезонной температурной стратификации поверхностных вод. Полученные различия функциональных характеристик фитопланктона обусловлены сезонными изменениями внутриклеточной концентра- ции пигментов и относительного содержания вспомогательных пигментов, размерной и видовой структурой сообщества фитопланктона. Закономерное изменение структурных и функциональных показателей фитопланктона в течение года отражает адаптивную реакцию микроводорослей на изменение условий их существования (в первую очередь освещенность и обеспеченность биогенными элементами) как на клеточном уровне, так и на уровне сообщества. Предлагаемая спектральная биооптическая модель оценки первичной продукции дает возможность учитывать не только изменение спектрального состава света, но и способности микроводорослей поглощать этот свет в ответ на изменение условий среды их обитания. Концептуально такая модель более реалистична, позволяет адекватно оценивать первичную продукцию и может быть использована и для оперативного мониторинга состояния акватории Черного моря, и для создания прогностических моделей развития его экосистемы.

\section{Благодарность}

Исследование выполнено при финансовой поддержке РФФИ в рамках научных проектов (р_юг_а № 14-45-01595, p_юг_а № 1445-01516, p_юг_a № 14-45-01594).

\section{Список литературы}

Иванов В.А., Белокопытов В.Н. (2011) Океанография Черного моря. НАН Украины, Морской гидрофизический институт, 209 c. [Ivanov V.A., Belokopytov V.N. (2011) Oceanography of the Black Sea. NAS, Marine Hydrophysical Institute, 209 p. (in Russian)]

Кубряков А.И., Суслин В.В., Чурилова Т.Я., Коротаев Г.К. (2012) Влияние оптических свойств воды на динамику вод верхних слоев Черного моря в период с 1985 до 2001 гг. Экологическая безопасность прибрежной и шельфовой зон и комплексное использование ресурсов шельфа, 26 (2): 224-255 [Kubryakov A.I., Suslin V.V., Churilova T.Ya., Korotaev G.K. (2012) The influence of sea water optical properties on dynamics of the Black Sea upper layers during 19852001 years. Ecological safety of coastal and shelf zones and comprehensive use of shelf resources [Ekologicheskaya bezopasnost pribrezhnoj i shelfovoj zon i kompleksnoe ispolzovanie resursov shelfa], 26 (2): 224-255 (in Russian)]

$$
-381-
$$


Маторин Д.Н., Рубин А.Б. (2012) Флуоресценции хлорофилла высших растений и водорослей. Ижевск, Изд-во ИКИ-РХД, 256 с. [Matorin D.N., Rubin A.В. (2012) Plant and algae chlorophyll fluorescence. Izhevsk, Publisher Regular and Chaotic Dinamics-Institute of Computer Science, 256 p. (in Russian)]

Суетин В.С., Суслин В.В., Королев С.Н., Кучерявый А.А. (2002) Оценка изменчивости оптических свойств воды в Черном море летом 1998 года по данным спутникового прибора SeaWiFS. Морской гидрофизический журнал, 6: 44-54 [Suetin V.S., Suslin V.V., Korolev S.N., Kucheryavyi A.A. (2002) Estimation of water optical properties variability in the Black Sea in summer 1998 using the measurements by satellite instrument SeaWiFS. Marine Hydrophysical Journal [Morskoi Gidrofizicheskii Zhurnal], 6: 44-54 (in Russian)]

Суслин В.В., Чурилова Т.Я., Сосик Х.М. (2008) Региональный алгоритм расчета концентрации хлорофилла $а$ в Черном море по спутниковым данным SeaWiFS. Морской экологический журнал, 2: 24-42 [Suslin V.V., Churilova T.Ya., Sosik H.M. (2008) The SeaWiFS algorithm of chlorophyll $a$ in the Black Sea. Marine Ecological Journal [Morskoi Ecologicheskii Zhurnal], 2: 24-42 (in Russian)]

Суслин В.В., Чурилова Т.Я. (2015) Трехканальный метод разделения поглощения света фитопланктоном и неживым органическим веществом: приложение к дистанционному зондированию в видимом диапазоне спектра. Современные проблемы оптики естественных вод: Tруды VIII Международной конференции. Санкт-Петербург, с. 199-204 [Suslin V.V., Churilova T.Ya. (2015) Three-band algorithm for splitting of light absorption by phytoplankton and colored detrital matter: application to ocean color remote sensing. Current Problems in Optics of Natural Waters: Proceedings of the VIII International Conference. St. Petersburg, p. 199-204 (in Russian)]

Финенко 3.3., Суслин В.В., Чурилова Т.Я. (2009) Региональная модель для расчета первичной продукции Черного моря с использованием данных спутникового сканера цвета SeaWiFS. Морской экологический журнал, 1: 81-106 [Finenko Z.Z., Suslin V.V., Churilova T.Ya. (2009) The regional model to calculate the Black Sea primary production using satellite color scanner SeaWiFS. Marine Ecological Journal [Morskoi Ecologicheskii Zhurnal], 1: 81-106 (in Russian)]

Чурилова Т.Я., Суслин В.В., Рылькова О.А. (2008) Параметризация поглощения света основными оптически активными компонентами в Черном море. Экологическая безопасность прибрежной и шельфовой зон и комплексное использование ресурсов шельфа, 16: 190-201 [Churilova T.Ya., Suslin V.V., Rylkova O.A. (2008) Parameterization of light absorption by all optically active components in the Black Sea. Ecological safety of coastal and shelf zones and complex use of resources of the shelf [Ekologicheskaya bezopasnost pribrezhnoj i shelfovoj zon i kompleksnoe ispolzovanie resursov shelfa], 16: 190-201 (in Russian)]

Чурилова Т.Я., Джулай А.А., Суслин В.В., Кривенко О.В., Ефимова Т.В., Муханов В.С., Рылькова О.А., Манжос Л.А. (2014) Биооптические показатели вод глубоководной части Черного моря: параметризация поглощения света фитопланктоном в осенний и летний периоды. Экологическая безопасность прибрежной и шельфовой зон и комплексное использование ресурсов шельфа, 28: 320-333 [Churilova T., Dzhuly A., Suslin V., Kryvenko O., Iefimova T., Mukhanov V., Rylkova O., Manjos L. (2014) Biooptical properties of the deep-water Black sea: parametrization of phytoplankton light absorption in summer and autumn. Ecological safety of coastal and shelf zones and complex 
use of resources of the shelf [Ekologicheskaya bezopasnost pribrezhnoj i shelfovoj zon i kompleksnoe ispolzovanie resursov shelfa], 28: 320-333 (in Russian)]

Чурилова Т.Я., Ефимова Т.В., Джулай А.А., Суслин В.В., Муханов В.С., Кривенко О.В. (2015) Биооптические характеристики вод Черного моря в зимний период. Современные проблемы оптики естественных вод: Труды VIII Международной конференции. Санкт-Петербург, с. 140-145 [Churilova T., Iefimova T., Dzguly A., Suslin V., Mukhanov V., Krivenko O. (2015) Bio-optical properties of the Black Sea in winter. Current Problems in Optics of Natural Waters: Proceedings of the VIII International Conference. St. Petersburg, p. 140-145 (in Russian)]

Babin M., Morel A., Claustre H., Bricaud A., Kolber Z., Falkowslu P.G. (1996) Nitrogen- and irradiance-dependent variations of the maximum quantum yield of carbon fixation in eutrophic, mesotrophic and oligotrophic marine systems. Deep-Sea Research, 41: 1241-1272

Bidigare R.R., Smith R.C., Baker K.S., Marra I. (1987) Oceanic primary production estimates from measurements of spectral irradiance and pigment concentrations. Global Biogeochemical Cycles, 1: $171-186$

Bricaud A., Babin M., Morel A., Claustre H. (1995) Variability in the chlorophyll-specific absorption coefficients of natural phytoplankton: Analysis and parameterization. Journal of Geophysical Research, 100 (C7): 13321-13332

Churilova T.Ya., Berseneva G.P. (2004) Absorption of light by phytoplankton, detritus, and dissolved organic substances in the coastal region of the Black Sea (July-August 2002). Physical Oceanography, 14 (4): 221-233

Churilova T.Ya., Berseneva G.P., Georgieva L.V. (2004) Variability in bio-optical characteristics of phytoplankton in the Black Sea. Oceanology, 44 (2): 192-204

Churilova T., Finenko Z., Tugrul S. (2008) Light absorption and quantum yield of photosynthesis during autumn phytoplankton bloom in the western Black Sea. Marine Ecological Journal [Morskoi Ecologicheskii Zhurnal], 7 (3): 75-86

Churilova T.Ya., Suslin V.V., Sosik H.M. (2009) A spectral model of underwater irradiance in the Black Sea. Physical Oceanography, 19 (6): 366-378

Churilova T., Suslin V. (2010) Parameterization of light absorption by all in-water optically active components in the Black Sea: Impact for underwater irradiance and primary production modelling. Coastal to Global Operational Oceanography: Achievements and Challenges: Proceedings of the fifth international conference on EuroGOOS, 28. UK, p. 199-205

Cullen J.J., Lewis M.R. (1988) The kinetics of algal photoadaptation in the context of vertical mixing. Journal Plankton Research, 10 (5): 1039-1063

Falkowski P.G. (1980) Primary productivity in the sea. New York, London, Plenum Press, 506 p.

Finenko Z., Churilova T., Lee R. (2005) Dynamics of the vertical distributions of chlorophyll and phytoplankton biomass in the Black Sea. Oceanology, 45 (1): 112-126

Gordon H.R., McGlunev W.R. (1975) Estimation of the depth of sunlight penetration in the sea for remote sensing. Applied Optics, 14: 413-416

Kiefer D.A., Mitchell B.G. (1983) A simple, steady state description of phytoplankton growth based on absorption cross section and quantum efficiency. Limnology and Oceanography, 28: 770-776

Kirk J.T.O. (1994) Light and photosynthesis in aquatic ecosystems. New York, Cambridge University Press, 509 p. 
Kok B. (1948) A critical consideration of the quantum yield of Chlorella photosynthesis. Enzymologia, 13: 1-56

Lewis M.R., Warnock R.E., Platt T. (1985) Absorption and photosynthetic action spectra for natural phytoplanktonic population: implication for production in the open ocean. Limnology and Oceanography, 30 (4): 794-806

Marra J., Trees C.C., Bidigare R.R., Barber R.T. (2000) Pigment absorption and quantum yields in the Arabian Sea. Deep Sea Research Part II, 47 (7-8): 1279-1299

Morel A., Prieur L. (1977) Analysis of variations in ocean color. Limnology and Oceanography, 22 (4): 709-722

Morel A., Bricaud A. (1981) Theoretical results concerning light absorption in a discrete medium, and application to specific absorption of phytoplankton. Deep-Sea Research, 28: 1375-1393

Morel A., Lazzara L., Gostan J. (1987) Growth rate and quantum yield time response for a diatom to changing irradiances (energy and color). Limnology and Oceanography, 32 (5): 1066-1084

Morel A. (1991) Light and marine photosynthesis: A spectral model with geochemical and climatological implications. Progress in Oceanography, 26: 263-306

Mueller J.L., Fargion G. (2000) Ocean optics protocols for satellite ocean color sensor validation, Revision 2, NASA. Technical Memorandum

Platt T., Caverhill C., Sathyendranath S. (1991) Basin scale estimates of ocean primary production by remote sensing: The North Atlantic. Journal of Geophysical Research, 96 (8): 15147-15159

O'Reilly J.E. \& 24 co-authors (2000) SeaWiFS Postlaunch Calibration and Validation Analyses, Part 3. NASA Technical Memorandum. 2000-206892, Vol. 11. Hooker S.B., Firestone E.R. (eds.) NASA Goddard Space Flight Center, 49 p.

Sakshaug E., Bricaud A., Dandonneau Y., Falkowski P.G., Kiefer D.A., Legendre L., Morel A., Parslow J., Takahashi M. (1997) Parameters of photosynthesis: definitions, theory and interpretation of results. Journal of Plankton Research, 19: 1637-1670

Smith R.C., Prezelin B.B., Bidigare R.R., Baker K.S. (1989) Bio-optical modeling of photosynthetic production in coastal waters. Limnology and Oceanography, 34 (8): 1524-1544

Wozniak B., Ficek D., Ostrowska M., Majchrowski R., Dera J. (2007) Quantum yield of photosynthesis in the Baltic: a new mathematical expression for remote sensing applications. Oceanologia, 49 (4): 527-542 